\title{
Sepiolite-supported nanoscale zerovalent iron to remediate decabromodiphenyl ether contaminated soil
}

\author{
$\mathrm{Na} \mathrm{Mu}{ }^{1}$, Dongsu $\mathrm{Bi}^{1}$, Rongbing $\mathrm{Fu}^{2}$, Xiaopin $\mathrm{Guo}^{2}$, Zhen $\mathrm{Xu}^{2}$ \\ ${ }^{1}$ Shanghai Institute of Technology, Shanghai 201418, China \\ ${ }^{2}$ Shanghai Academy of Environmental Sciences, Shanghai 200233, China
}

Keywords: sepiolite-supported nanoscale zerovalent iron; decabromodiphenyl ether contamination; soil; remediation; mechanism

\begin{abstract}
The removal of decabromodiphenyl ether (BDE-209) from contaminated soil using sepiolite-supported nanoscale zero-valent iron was investigated. The experimental results indicated that the removal efficiency of BDE-209 from soil was greater than that of the nanoscale zerovalent iron (nZVI). The removal efficiency of BDE-209 from soil increased with increasing dosage of sepiolite-supported nZVI particles and decreasing $\mathrm{pH}$. Adsorption on sepiolite-supported nZVI also played a role in the removal of BDE-209 from soil. This study indicated that the sepiolite-supported nZVI particles had potential applications in remediation polybrominateddiphenyl ethers (PBDEs) contaminated soil.
\end{abstract}

\section{Introduction}

Polybrominated diphenyl ethers (PBDEs), is the most representative of a class of widely existent persistent organic pollutants (POPs) in the environment. PBDEs have been found in human and animal blood and tissues (Mariussen et al. 2008) because of their bioaccumulation, persistence, and high hydrophobicity (Luo et al. 2009). Concerns about the potential effect of PBDEs on human have increased due to PBDEs threatened reproductive health and caused neurotoxicity (Darnerud et al. 2001). Decabromodiphenyl ether (BDE-209) makes up 80\% of the total consumption of PBDEs normally used (Keum \&Li 2005) and has become a possible human carcinogen. Therefore, it is crucial for people to find an efficient and cost-effective method to remediate PBDEs contaminated soil, especially BDE-209 contamination.

Soils represent a major sink for organic contaminants in the environment (Huang et al. 2009), PBDEs can easily accumulate in soil and sediment and tend to release to the environment (Vonderheide et al. 2008). Recently, nanoscale materials (e.g., nanoscale zerovalent iron) and their compounds have become a promising approach to treat PBDEs-polluted soil and water (Trujillo-Reyes et al. 2014). Nanoscale zerovalent iron (nZVI) has been used to remove halogenated organic compounds (Li \&Zhu 2014, Lowry \&Johnson 2004) because of its higher reactivity, larger specific surface area, and higher degradation efficiency. However, there are some problems using nZVI particles to remove organic contaminants. For instance, nZVI particles can easily agglomerate in the preparation and application process because of their nanosize and poor dispersibility in water. In addition, nZVI particles are easily oxidized in air because of their high activity (Fei et al. 2012, Xiao et al. 2015). Therefore, to minimize such adverse effects on nZVI particles, mesoporous silica microspheres, resins have been used as supporters to facilitate the high oxidation resistance and dispersion in solution (Luo et al. 2013, Qiu et al. 2011). Yu and Gu et al. (Yu et al. 2012) prepared smectite clay-templated subnanoscale zero-valent iron and used it to remove BDE-209.

Up to now, however, researchers have primarily concentrated their mind on removing BDE-209 from aqueous solution rather than from soil. Therefore, the objective of this study was to investigate the removal of BDE-209 from contaminated soil using sepiolite-supported nZVI. Sepiolite had stability in air, good dispersibility in water, cost-effectiveness and good adsorption properties (Bingol et al. 2010). Some influence factors, such as sepiolite-supported nZVI addition and initial $\mathrm{pH}$ of soil solution were investigated. This study helps people evaluate the feasibility of sepiolite-supported nZVI particles in remediating PBDEs contaminated soil. 


\section{Materials and Methods}

Chemical and reagents

A standard solution of BDE-209 was purchased from Accustandard Inc.(New Haven, CT) and used to establish the standard curve. Decabromodiphenyl ether (BDE-209>85\%), ferric chloride hexahydrate $\left(\mathrm{FeCl}_{3} \cdot 6 \mathrm{H}_{2} \mathrm{O}>99 \%\right)$, sodium borohydrite $\left(\mathrm{NaBH}_{4}>96 \%\right)$, n-hexane (HPLC grade), ethanol (GR>99.8\%), and hydrochloric acid ( $\mathrm{HCl} 37 \%$ ) were obtained from Sinopharm Chemical Reagent Co. Ltd (Shanghai, PRC). Sepiolite was purchased from Nanyang Boxing Mining Co., Ltd (Hebei, PRC).

Soil sample preparation

The soil sample was collected from the Fengxian District in Shanghai, China. Before use, the raw soil was sieved by a 60 mesh standard sieve and then saved in a desiccators for future use. The detection results shown that the soil sample was hardly containing BDE-209 and its physico-chemical properties was shown in Table 1.

Table 1 Physical and chemical properties of the soil samples.

\begin{tabular}{ccccc}
\hline & Soil type & $\mathrm{pH}$ & The organic matter (\%) & Moisture content(\%) \\
\hline Raw soil & loess & 8.31 & 1.19 & 1.38 \\
\hline
\end{tabular}

BDE-209 contaminated soil samples were prepared through the following steps: $100 \mathrm{~mL}$, $200 \mu \mathrm{g} / \mathrm{L}$ of BDE-209 solution was mixed with $100 \mathrm{~g}$ dried soil and agitated until the mixture was dried to a constant weight, and then got $200 \mathrm{ng}$ (BDE209) /g (dried soil). The error of repeated preparations was no more than $5 \%$.

Preparation sepiolite-supported nZVI particles

In the prepared process, 9 g sepiolite (modified by $\mathrm{HCl}$ ) was mixed with $150 \mathrm{~mL}$ of $0.1 \mathrm{M} \mathrm{FeCl}_{3}$ under acidic conditions ( $\mathrm{pH} \sim 4$ ) for $12 \mathrm{~h}$, and the mixture was centrifuged to remove the supernatant and repeated several times with deoxygenated deionized water. Fe-sepiolite was dissolved in $150 \mathrm{~mL}$ water again, and the $\mathrm{pH}$ of mixture was adjusted to 3.0. Then, $150 \mathrm{~mL}, 0.4 \mathrm{M}$ $\mathrm{NaBH}_{4}$ was added drop-wise into the mixture under vigorous agitation and a nitrogen atmosphere. The sepiolite-supported nZVI solution was centrifuged and rinsed several times with water. Finally, the prepared sepiolite-supported nZVI particles were dried in vacuum overnight at $60^{\circ} \mathrm{C}$ before use. Deoxygenated water used in the experiment was boiled for $0.5 \mathrm{~h}$ and subsequently purged with $\mathrm{N}_{2}$ for another $0.5 \mathrm{~h}$. As a comparison, bare nZVI was synthesizedby drop-wise adding anaqueous solution of $1.6 \mathrm{M} \mathrm{NaBH}_{4}$ to the $1 \mathrm{M} \mathrm{FeCl}_{3} \cdot 6 \mathrm{H}_{2} \mathrm{O}$ solution at $28^{\circ} \mathrm{C}$ with continuous stirring and a stream of $\mathrm{N}_{2}$.

Characterization

The size and morphology of nZVI, sepiolite-supported nZVI particles, and sepiolite were characterized by a transmission electron microscope (TEM,JEM 2011,Jeol, Japan). The crystalline phase of nZVI, modified sepiolite, and sepiolite-supported nZVI particles were determined using an X-ray diffractometer (Cu K $\alpha$ radiation, X'Pert PW 3040/60, PANalytical, the Netherlands). The iron content of the prepared sepiolite-supported nZVI was measured with $\mathrm{HCl}-\mathrm{HNO}_{3}-\mathrm{HF}$ digestion and an analysis with ICP (Optima 7000DV, Perkin-Elmer, USA).

Reaction of BDE-209 with sepiolite-supported nZVI

The removal of BDE-209 from soil was studied under different reaction conditions, including sepiolite-supported nZVI dosages and soil solution $\mathrm{pH}$. Batch experiments were proceeded to remediate the BDE-209 polluted soil with a group of $10 \mathrm{~mL}$ centrifuge tubes, which contained a given amount of the prepared particles (containing $13 \mathrm{mg} / \mathrm{g}$ of $\mathrm{nZVI}$ ), $2 \mathrm{~g}$ dried soil and $2 \mathrm{~mL}$ deoxygenated water. The mixtures were placed in a thermostat steam batch vibrator (ZD-85, China) at a speed of $200 \mathrm{rpm}$ at $28^{\circ} \mathrm{C}$. In a given time interval, several tubes were taken out of the vibrator. The samples were dried, and then using n-hexane to extract the residual BDE-209, the final volume of the extracts was adjusted to $0.5 \mathrm{~mL}$ under a gentle $\mathrm{N}_{2}$ stream.

Analysis methods

The BDE-209 concentration was determined using a SHIMADZU gas chromatograph/mass 
spectrometer (GCMG-QP2010 SE, SHIMDZHU, Japan); the system was equipped with a MXT-1 capillary column $(15 \mathrm{~m} \times 0.25 \mathrm{~mm} \times 0.1 \mu \mathrm{m})$. The column temperature was maintained at $110^{\circ} \mathrm{C}$ for 2 min, increased to $250^{\circ} \mathrm{C}$ at a rate of $40^{\circ} \mathrm{C} / \mathrm{min}$, increased to $300^{\circ} \mathrm{C}$ at a rate of $10^{\circ} \mathrm{C} / \mathrm{min}$, maintained at $300^{\circ} \mathrm{C}$ for $2 \mathrm{~min}$, increased to $325^{\circ} \mathrm{C}$ at a rate of $40^{\circ} \mathrm{C} / \mathrm{min}$, maintained at $325^{\circ} \mathrm{C}$ for $5 \mathrm{~min}$. The injection port temperature was set at $280^{\circ} \mathrm{C}$. The samples were introduced through a splitless injector ( $1 \mu \mathrm{L}$ splitless mode). The flow rate of helium carrier gas was $1.6 \mathrm{~mL} / \mathrm{min}$. The ion source and interface temperatures were set at $250^{\circ} \mathrm{C}$ and $290^{\circ} \mathrm{C}$, respectively.

\section{Results and discussion}

Characterization of synthetic material

The TEM pictures of nZVI, sepiolite-supported nZVI, and modified sepiolite were shown in Figure 1. It was observed that the nZVI particles (Figure 1(a)) appeared to have primarily spherical shapes in the size range of 20 to $60 \mathrm{~nm}$ and form aggregates because of their high surface energies and magnetic interactions. The TEM image of sepiolite-supported nZVI is shown in Figures 1(b), and this of the modified sepiolite are shown in Figures 1(c). The nZVI dots on the external surfaces of sepiolite were $5-20 \mathrm{~nm}$. The interlayer nZVI particles had sizes of $0.01 \sim 1 \mathrm{~nm}$ based on the XRD pattens.
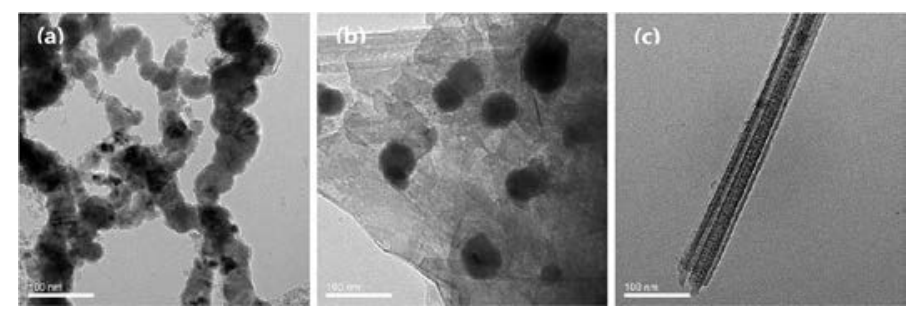

Figure 1. TEM images of (a) nZVI, (b) sepiolite-supported nZVI, and (c) modified sepiolite.

XRD patterns (Figure 2) indicated that the nZVI contained primarily body-centered cubic $\alpha$-Fe. NZVI showed characteristic peaks at $2 \theta=44.8^{\circ}, 65.1^{\circ}$, and $82.4^{\circ}$, which corresponded to cubic $\alpha$-Fe-110, -200 and -211, respectively. No apparent peak of $\mathrm{Fe}^{0}$ was found in the XRD pattern of the sepiolite-supported nZVI, which indicated that the amount of nZVI supported on sepiolite was notably small.

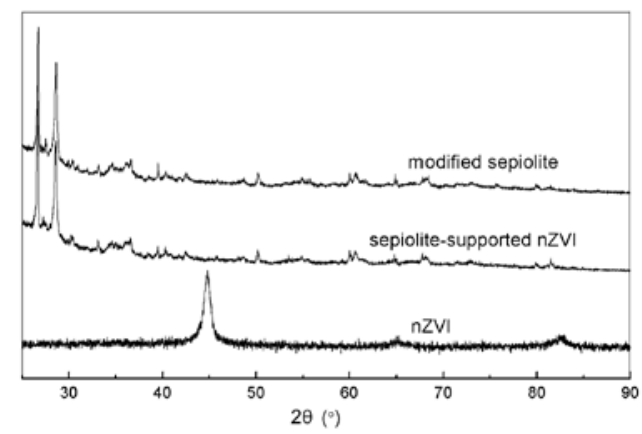

Figure 2. XRD patterns of modified sepiolite, sepiolite-supported nZVI and nZVI.

Comparison of the BDE-209 removal efficiency from soil of different materials

The removal of BDE-209 with sepiolite, modified sepiolite, sepiolite-supported nZVI and nZVI from soil over time were investigated: both sepiolite-supported nZVI and nZVI contained the same amount of $\mathrm{Fe}^{0}$ (2.6mg), the addition of sepiolite, modified sepiolite, sepiolite-supported nZVI was $0.2 \mathrm{~g}$ (Figure 3). About 29.44\% of BDE-209 was removed from soil after a $16 \mathrm{~d}$ by sepiolite-supported nZVI. However, only $10.93 \%$ of BDE-209 was removed by nZVI. This result 
showed that the sepiolite-supported nZVI had better removal efficiency than nZVI because the nZVI tended to form agglomerates, which decreased the nZVI specific surface area. The removal efficiency of BDE-209 by the modified sepiolite was $16.66 \%$, this indicated that the raction of BDE-209 with sepiolite-supported nZVI was a combination of adsorption and reduction.

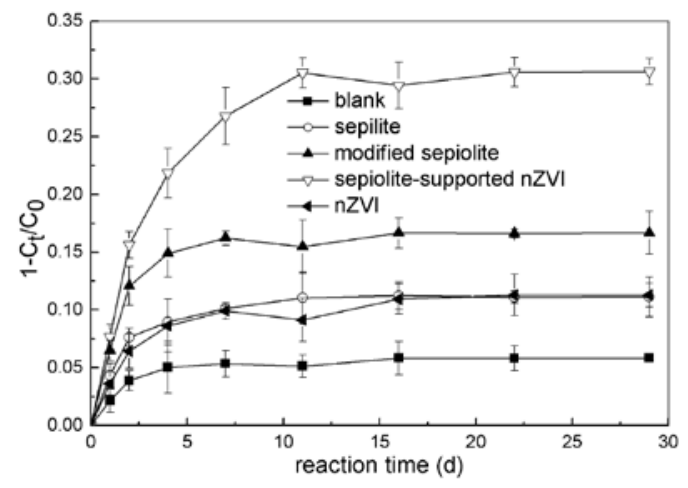

Figure 3. Removal efficiency of BDE-209 by nZVI, sepiolite, modified sepiolite, and sepiolite-supported nZVI.

Effect of adding sepiolite-supported nZVI

The effect of the sepiolite-supported nZVI addition on the removal of BDE-209 from soil was shown in Figure 4. The removal efficiency of BDE-209 increased with the increasing amount of sepiolite-supported nZVI. The removal efficiency was about $48.64 \%$ at $16 \mathrm{~d}$ when $0.4 \mathrm{~g}$ sepiolite-supported nZVI was added, whereas, approximately 15.74\% of BDE-209 was removed with $0.1 \mathrm{~g}$ sepiolite-supported nZVI. This could be explained by the increased specific surface area, adsorption and reaction sites of the sepiolite-supported nZVI. Thus, the BDE-209 removal was accelerated when the material addition increased.

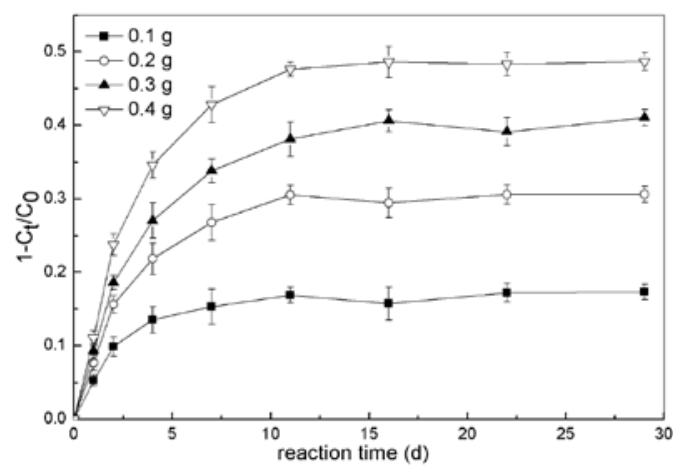

Figure 4. Effect of sepiolite-supported nZVIaddion on the BDE209 removal efficiency.

Effect of the initial $\mathrm{pH}$

The removal process of BDE-209 from soil by sepiolite-supported nZVI was an acid-driven reaction (Figure 5). The removal efficiency decreased with increasing $\mathrm{pH}$, and the maximum efficiency was observed about $41.9 \%$ in $\mathrm{pH} 4$ at $16 \mathrm{~d}$. This indicated that the removal reaction of BDE-209 using sepiolite-supported nZVI was effectively governed by $\mathrm{H}^{+}$. In an acidic environment, the sepiolite-supported nZVI reacted with $\mathrm{H}^{+}$to produce the activated $\mathrm{H}$ (Choe et al. 2001), which could reduce BDE-209. When the reaction continued, the $\mathrm{pH}$ of soil solution increased due to the consumption of $\mathrm{H}^{+}$. 


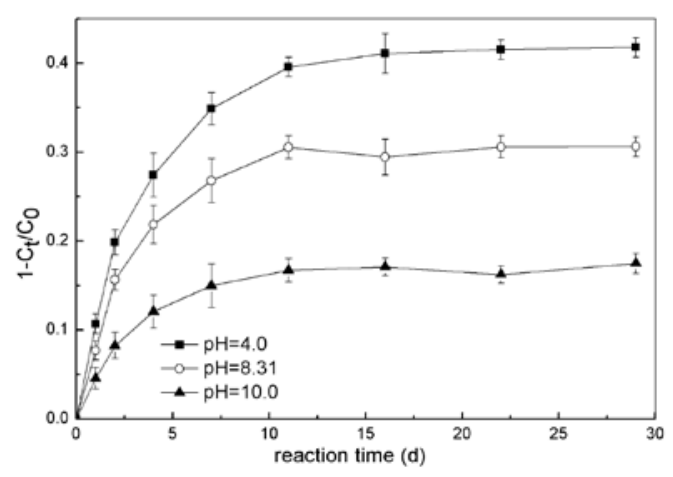

Figure 5. Effect of the initial soil solution pH on BDE209 removal efficiency.

\section{Conclusion}

The present study demonstrated a new method to immobilize nZVI on sepiolite to enhance the activity of nZVI for the in situ remediation of BDE-209 from soil. The results showed that BDE-209 in the soil was removed with sepiolite-supported nZVI and reached the maximum removal efficiency within $29 \mathrm{~d}$, and the removal efficiency of BDE-209 was faster than nZVI under the same conditions. The removal efficiency of BDE-209 increased with the increasing amount of sepiolite-supported nZVI and low soil solution $\mathrm{pH}$. This study supplies a promising technology for in site remediation PBDEs-contaminated soil. However, the ecotoxicity of the remediated soilshould be taken into consideration. Further evaluating by more tests before field application is needed.

\section{Acknowledgments}

This research was supported by the National Nature Science Foundation of China (Grant No. 41372262) and the Nature Science Foundation of Shanghai (Grant No. 13ZR1435100).

Corresponding author: Rongbing Fu

Tel: +86 13816036746; fax: +86 2164360761 .

E-mail addresses: rongermmfu@163.com (R. Fu).

\section{References}

[1] Bingol D, Tekin N, Alkan M (2010): Brilliant Yellow dye adsorption onto sepiolite using a full factorial design. Applied Clay Science 50, 315-321

[2] Choe S, Lee S-H, Chang Y-Y, Hwang K-Y, Khim J (2001): Rapid reductive destruction of hazardous organic compounds by nanoscale $\mathrm{Fe}<\sup >0</$ sup $>$. Chemosphere 42, 367-372

[3] Darnerud PO, Eriksen GS, Jóhannesson T, Larsen PB, Viluksela M (2001): Polybrominated diphenyl ethers: occurrence, dietary exposure, and toxicology. Environmental Health Perspectives 109, 49-68

[4] Fei X, Cao L, Zhou L, Gu Y, Wang X (2012): Degradation of bromamine acid by nanoscale zero-valent iron (nZVI) supported on sepiolite. Water Science \& Technology 66, 2539-2545

[5] Huang H, Zhang S, Christie P, Wang S, Xie M (2009): Behavior of decabromodiphenyl ether (BDE-209) in the soil- plant system: Uptake, translocation, and metabolism in plants and dissipation in soil. Environmental science \& technology 44, 663-667

[6] Keum Y-S, Li QX (2005): Reductive debromination of polybrominated diphenyl ethers by zerovalent iron. Environmental science \& technology 39, 2280-2286

[7] Li B, Zhu J (2014): Removal of p-chloronitrobenzene from groundwater: Effectiveness and 
degradation mechanism of a heterogeneous nanoparticulate zero-valent iron (NZVI)-induced Fenton process. Chemical Engineering Journal 255, 225-232

[8] Lowry GV, Johnson KM (2004): Congener-specific dechlorination of dissolved PCBs by microscale and nanoscale zerovalent iron in a water/methanol solution. Environmental Science \& Technology 38, 5208-5216

[9] Luo S, Qin P, Shao J, Peng L, Zeng Q, Gu J-D (2013): Synthesis of reactive nanoscale zero valent iron using rectorite supports and its application for Orange II removal. Chemical Engineering Journal 223, 1-7

[10] Luo X-J, Liu J, Luo Y, Zhang X-L, Wu J-P, Lin Z, Chen S-J, Mai B-X, Yang Z-Y (2009): Polybrominated diphenyl ethers (PBDEs) in free-range domestic fowl from an e-waste recycling site in South China: levels, profile and human dietary exposure. Environment international 35, 253-258

[11] Mariussen E, Fjeld E, Breivik K, Steinnes E, Borgen A, Kjellberg G, Schlabach M (2008): Elevated levels of polybrominated diphenyl ethers (PBDEs) in fish from Lake Mjøsa, Norway. Science of the total environment 390, 132-141

[12] Qiu X, Fang Z, Liang B, Gu F, Xu Z (2011): Degradation of decabromodiphenyl ether by nano zero-valent iron immobilized in mesoporous silica microspheres. Journal of hazardous materials 193, 70-81

[13] Trujillo-Reyes J, Peralta-Videa J, Gardea-Torresdey J (2014): Supported and unsupported nanomaterials for water and soil remediation: Are they a useful solution for worldwide pollution? Journal of hazardous materials 280, 487-503

[14] Vonderheide AP, Mueller KE, Meija J, Welsh GL (2008): Polybrominated diphenyl ethers: Causes for concern and knowledge gaps regarding environmental distribution, fate and toxicity. Science of the Total Environment 400, 425-436

[15] Xiao J, Gao B, Yue Q, Gao Y, Li Q (2015): Removal of trihalomethanes from reclaimed-water by original and modified nanoscale zero-valent iron: Characterization, kinetics and mechanism. Chemical Engineering Journal 262, 1226-1236

[16] Yu K, Gu C, Boyd SA, Liu C, Sun C, Teppen BJ, Li H (2012): Rapid and extensive debromination of decabromodiphenyl ether by smectite clay-templated subnanoscale zero-valent iron. Environmental science \& technology 46, 8969-8975 